\title{
Avaliação da suscetibilidade aos movimentos de massa a partir de variáveis morfométricas na interface entre 0 planalto meridional e a depressão central da região do Vale do Taquari - Rio Grande do Sul
}

Evaluation of susceptibility to mass movements from morphometric variables at the interface between the southern plateau and the central depression of the Vale do Taquari region - Rio Grande do Sul

\section{Tainara Godoy de Souza' ${ }^{\mathbb{D}}$, Áquila Ferreira Mesquita"ID , Alexandre Felipe Bruch'iD \\ 'Centro de Engenharias, Universidade Federal de Pelotas, Pelotas, RS, Brasil \\ "Departamento de Geologia e Recursos Naturais, Instituto de Geociências, Universidade Estadual de Campinas, Campinas, SP, Brasil}

\section{RESUMO}

A ocorrência de desastres ambientais no Brasil, a partir de fenômenos naturais, vêm aumentando no decorrer dos anos. Dentre esses fenômenos, estão os movimentos gravitacionais de massa que, além do alto poder destrutivo, pode provocar danos socioeconômicos. As variáveis morfométricas são comumente utilizadas em análises geomorfológicas, principalmente no diagnóstico de áreas suscetíveis a esses processos. Sendo assim, o trabalho tem como objetivo identificar áreas suscetíveis aos movimentos de massas na interface entre o planalto meridional e a depressão central da região do Vale do Taquari-RS, a partir de variáveis geomorfométricas em escala de 1:250.000. Essa análise integra produtos de sensoriamento remoto e geoprocessamento, que se torna um método eficaz e de baixo custo. Em ambiente SIG (Sistema de Informações Geográficas) foi realizada álgebra de mapas que utiliza métodos estatísticos AHP (Analytical Hierarchy Process) e Delphi, no qual validaram a ponderação, e a hierarquia de variáveis. O produto final é uma carta de avaliação da suscetibilidade ambiental aos movimentos de massa da região em estudo. Na carta é observado que a região apresenta alto grau de suscetibilidade na maior parte das vertentes. Com esses dados é possível idealizar um planejamento e gerenciamento adequado do território, fornecendo maior segurança na ocupação nessas áreas.

Palavras-chave: Suscetibilidade; Variáveis Morfométricas; Gestão Territorial

\section{ABSTRACT}

The occurrence of disasters in Brazil by natural processes has been increasing along the years. One of these phenomena is mass movements, a destructive phenomenon which may cause damage to socioeconomic. The morphometric variables are becoming useful in geomorphologic analysis, mainly in 
diagnosis of susceptible areas to those processes. This way, the objective of this work is to identify susceptible areas of mass movements in the interface between meridional plateau and the central depression in Vale do Taquari region, using geomorphometric variable at a scale of 1:250.000. This morphometric analysis contains Remote Sensing and geoprocessing, so it becomes an effective and low cost method. GIS software (Geographic Information System) was used to maps algebra from the statistical methods AHP (Analytical Hierarchy Process) and Delphi, in which pondering and the hierarchy of influential variables in this analysis. The final product is an analysis map of susceptibility to mass movements in the mentioned region. In the map it is observed that the region has a high degree of susceptibility in most aspects. With this data it is possible to carry out a proper planning and management of the territory, providing more safety to the occupation of those areas.

Keywords: Susceptibility; Morphometric Variables; Territorial Management

\section{INTRODUÇÃO}

O aumento de desastres ambientais, a partir de fenômenos naturais, tem se tornado uma grande preocupação em todo território nacional. Entre esses fenômenos, encontra-se o processo de movimentos gravitacionais de massa que geralmente está associado à ocorrência de fortes chuvas e, consequentemente, pode provocar danos irreversíveis que incluem perda de vidas e o prejuízo a atividades socioeconômicas desenvolvidas (BITAR, 2014). Ou seja, o conjunto entre eventos climáticos, características geomorfológicas e má ocupação territorial de centros populacionais devem ser melhor estudados e analisados a fim de reduzir e/ou evitar desastres naturais de grande magnitude.

Dada a gravidade desse tipo de evento natural, o governo federal estipulou a Lei $N^{\circ}$ 12.608 (10 de abril de 2012) que institui a Política Nacional de Proteção e Defesa CivilPNPDEC e o Conselho Nacional de Proteção e Defesa Civil - CONPDEC, no qual autoriza a criação de sistemas de informações e monitoramento de desastres. A lei introduz diretrizes que tem como prioridade desenvolver ações preventivas relacionadas à minimização de acidentes. Um dos principais objetivos caracteriza-se em identificar e avaliar ameaças, suscetibilidades e vulnerabilidades a desastres de eventos naturais, de modo a evitar ou minimizar desastres de movimentos de massa, inundações e erosão linear.

Especificamente em relação aos movimentos gravitacionais, sabe-se que a forma de vales e encostas possui grande influência na instabilidade e desenvolvimento desses processos (SILVA et.al 2007). Assim, a análise das variáveis morfométricas torna-se uma boa ferramenta para análises geomorfológicas e mapeamento de potenciais áreas de ocorrência desses fenômenos (OZDEMIR, 2011). Por esse motivo, a interação entre as 
variáveis morfométricas é fundamental, pois suas informações irão se complementar gerando uma carta de dados com diferentes graus de suscetibilidade.

De acordo com Carmo et al. (2016), a análise geomorfológica, utilizando variáveis morfométricas, possibilita inferir a suscetibilidade de um terreno por meio do comportamento que ele possa apresentar em função de sua forma geométrica, permitindo assim um prognóstico preventivo às suscetibilidades que o terreno possa oferecer. No entanto, outros fatores também podem controlar o desenvolvimento dessas formas e devem ser avaliados para o cálculo da suscetibilidade. Exemplo disso são as características lito-estruturais dos substratos rochosos, no qual podem potencializar, ou não, a movimentação de massa em função das suas características texturais e/ou estruturais (falhas, fratura, foliações, dobras e etc.). Dessa forma, as variáveis morfométricas aliadas à geologia podem ser excelentes ferramentas de delimitação das áreas suscetíveis aos danos ambientais, como os de movimentos de massa, principalmente em áreas serranas com relevos acidentados e/ou ondulados e com encostas fortemente entalhadas (KAWABATA e BANDIBAS, 2009).

O presente trabalho integrou técnicas do geoprocessamento que em conjunto com produtos do Sensoriamento Remoto possibilitam a realização do zoneamento de áreas suscetíveis ao movimento de massa, a partir da correlação entre as variáveis morfométricas do terreno. Este recurso utiliza a modelagem matemática a partir de parâmetros físicos, que são tratados com dados estatísticos e relacionados a base bibliográfica da área em estudo, gerando índices. A correlação entre esses índices fomentou a carta de suscetibilidade, a qual pode ser utilizada no auxílio de projetos que visam o monitoramento e gerenciamento territorial.

O trabalho tem como principal objetivo identificar áreas suscetíveis aos movimentos de massas na interface entre o planalto meridional e a depressão central da região, a partir de variáveis morfométricas geomorfológicas. No entanto, o estudo não visa caracterizar os diferentes tipos de movimentos de massa, uma vez que, para isso, seria necessário um estudo geomecânico detalhado (geometria da rede de fraturas, índices mecânicos do solo e etc.), não compatíveis com a escala de trabalho proposta. Dessa maneira, foi necessário: i) criar mapas temáticos de variáveis do meio físico (declividade, curvatura vertical, curvatura horizontal, densidade de lineamentos e 
hipsometria) que possam influenciar o processo de movimento de massa; ii) gerar uma carta de avaliação da suscetibilidade ambiental aos movimentos de massa, a partir da interação dos mapas temáticos empregando a análise multicritérios e; iii) Compreender como ocorre a distribuição de áreas de alta suscetibilidade à movimentação de massa e seus potenciais danos ao desenvolvimento socioeconômico da região estudada.

\section{2 ÁREA DE ESTUDO}

A área do estudo abrange parte da região do Vale do Taquari, que fica localizada na porção central do Rio Grande do Sul a $117 \mathrm{~km}$ de Porto Alegre (Figura 1). Compreende 28 dos 36 municípios dessa região que em conjunto abrangem uma área de 2683,366 km². Conforme as estimativas populacionais do IBGE (2017), há cerca de 351.999 habitantes (3,11\% da população do Rio Grande do Sul), de maneira que os municípios mais populosos são Lajeado, Estrela, Teutônia, Taquari, Encantado e Arroio do Meio, que respondem por $60,63 \%$ do total da população regional.

Figura 1 - Mapa de localização da área de estudo

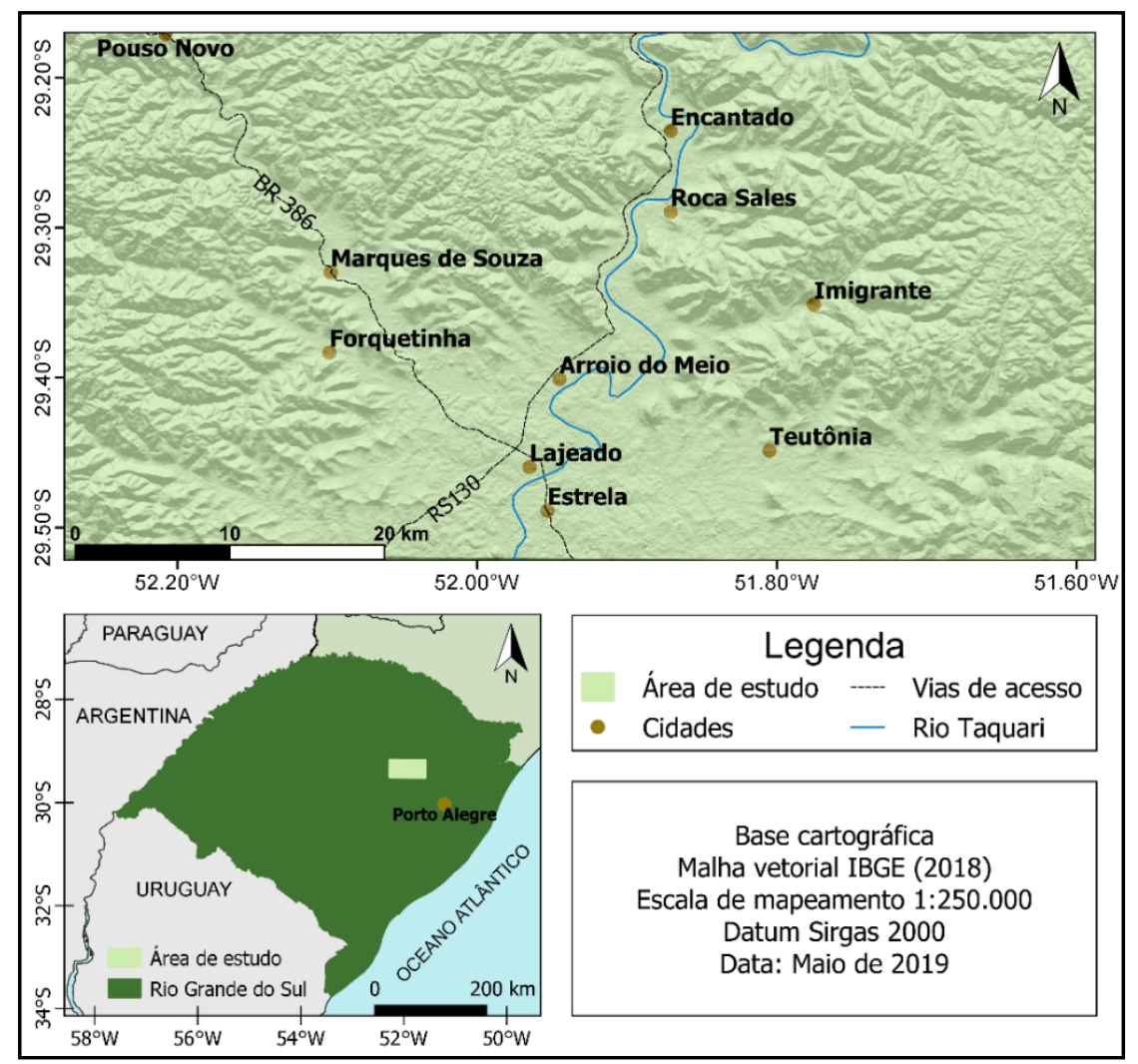

Fonte: autores (2020) 
O Vale do Taquari possui uma localização estratégica, com fácil acesso a outras regiões do Estado do Rio Grande do Sul e demais regiões do País por uma desenvolvida malha ferroviária e rodoviária. Por se tratar de um centro regional com grande desenvolvimento socioeconômico, principalmente na agroindústria, é de suma importância a compreensão da distribuição territorial dessas atividades.

Em função disso, associar os processos de superfície com índices morfométricos do relevo, perfaz uma técnica de zoneamento para o reconhecimento de áreas suscetíveis na região, o que pode auxiliar na identificação e gerenciamento de possíveis zonas de risco. Tendo em vista as limitações ambientais determinadas a partir da carta de suscetibilidade, o planejamento adequado fornecerá maior segurança na ocupação nessas áreas.

A região do Vale do Taquari está inserida no domínio de duas unidades geomorfológicas: o Planalto Meridional e a Depressão Central. Seu relevo abrange a Escarpa ou Encosta do Planalto, morros testemunhos, patamares e terraços fluviais (MACHADO et al., 2014). A área está inserida no contexto geológico do Grupo Serra Geral (Juno-Cretáceo da Bacia do Paraná), caracterizado pela Formação Caxias e Formação Gramado, ambas constituídas por rochas vulcânicas (HOFF et al., 2007) (Figura 2).

Figura 2 - Mapa de geologia local da área de estudo

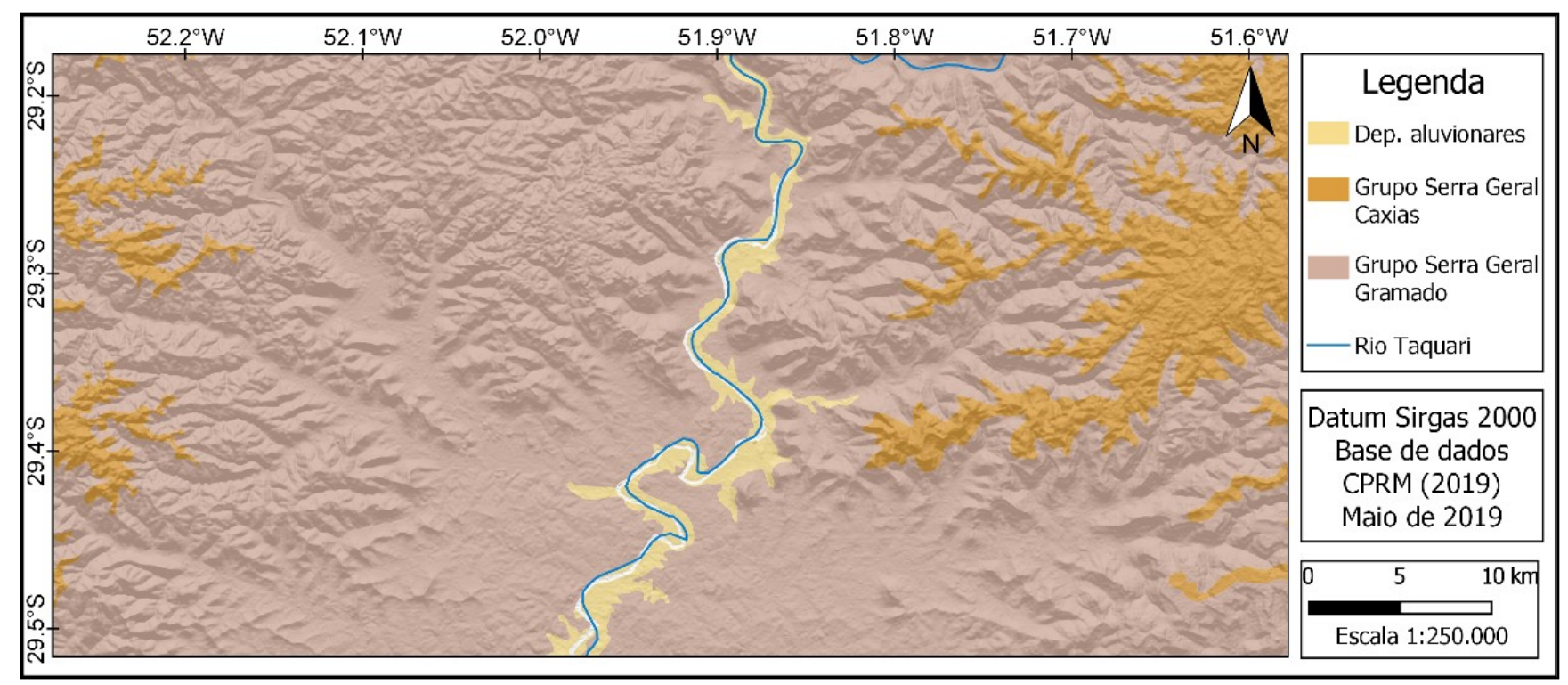

Fonte: autores (202 
O Planalto Meridional é composto por derrames do Grupo Serra Geral que cobrem parte da Bacia do Paraná uma área aproximada de 200.000 km², abrangendo a porção norte, noroeste e nordeste do Estado. Essa unidade também contorna outras unidades litoestratigráficas da Depressão Central, até os limites mais setentrionais do Estado (HOFFMANN et al., 1992). Essa unidade possui altitudes maiores de 1300m que diminuem em direção leste-oeste até cerca de 700m de altitude. (MOREIRA, 2003).

A outra unidade geomorfológica que compõe a área de estudo é a Depressão Central localizada na região central do Estado e representa um extenso corredor de baixa altitude (máximo 100 m). A Depressão Central pode ser observada como um relevo predominantemente plano e, por vezes, suavemente ondulado. Esse compartimento é composto primordialmente por um substrato sedimentar do Mesozoico ( 65 Ma.) não cobertos pelos derrames do Grupo Serra Geral, característica não observada em mapeamentos geológicos na região em estudo (BECKER e NUNES, 2012).

\section{FATORES CONDICIONANTES AOS PROCESSOS DE MOVIMENTOS DE MASSA}

Entre a variedade de condicionantes do meio físico consideradas para a construção de cartas de suscetibilidade, distinguem-se três fatores que induzem aos movimentos de massa. São eles declividade, curvatura de encosta e densidade de lineamentos estruturais (correlatos a fraturas, juntas, zonas de falhas e outras descontinuidades), que refletem, respectivamente, na influência combinada de aspectos geomorfológicos, hidrológicos, pedológicos e geológicos (STABILE et al., 2013).

\subsection{Fatores Geológicos}

O fator geológico retrata sobre os tipos de materiais presentes no substrato, assim como suas características texturais e estruturais. A depender do ângulo de mergulho e da direção de anisotropias do substrato (foliações, falhas e fraturas) em relação às vertentes, 
superfícies de rupturas em maciços rochosos podem ser desenvolvidas, o que facilita o processo de movimentação de blocos (FERNANDES e AMARAL, 1996).

No zoneamento da suscetibilidade aos movimentos gravitacionais de massa em áreas com o comportamento geológico relativamente homogêneo, o fator relacionado às estruturas geológicas mais comumente empregado em modelos estatísticos é a densidade de lineamentos (STABILE et al., 2013). Os lineamentos são feições lineares de uma superfície com forma retilínea ou ligeiramente curva, e que refletem provavelmente estruturas de subsuperfície (O'LEARY et al., 1976). Essas feições podem também interferir na resistência das rochas ao intemperismo e à erosão. Dessa forma, a área com alta densidade de lineamentos, possivelmente apresentará um substrato mais cominuído e intemperizado, o que variavelmente facilita o processo de movimentação de massa por agentes erosivos e/ou gravidade.

\subsection{Fatores Geomorfológicos}

A geometria das vertentes atua direta e indiretamente no escoamento superficial e no desenvolvimento dos processos erosivos, apresentando uma relação importante na taxa de remobilização de materiais e natureza dos processos geomórficos e pedogenéticos (IBGE, 2009). No estudo de análises à suscetibilidade a ocorrência de fluxos gravitacionais, as curvaturas verticais e curvaturas horizontais são fatores importantes, pois estão diretamente ligadas aos tipos de fluxos de água superficiais e subsuperficiais, a saturação do solo e consequentemente à ocorrência de deslizamentos de massa. (STABILE et al., 2013).

As formas de terreno afetam diretamente no desencadeamento dos movimentos de massa, pois estão relacionados ao tipo de substrato e a geometria dos fluxos controlada pelas curvaturas. Dessa forma, a análise da relação entre concavidade, convexidade, segmento retilíneo e declividade da vertente define pontos e graus diferentes de suscetibilidade aos movimentos de massa, bem como os locais prováveis para deposição dos sedimentos decorrentes desses processos (RITTER et al., 2002). As 
formas que o terreno apresenta é o resultado da combinação entre as curvaturas vertical e horizontal. Como produto final da associação da curvatura vertical (côncavo, retilíneo e convexo) e curvatura horizontal (convergente, planar e divergente), se estabelece nove classes distintas para as formas do terreno (Figura 3) (VALERIANO, 2008a).

A curvatura vertical expressa o formato da vertente quando analisada em perfil, e pode ser classificada quanto à forma côncava, retilínea e convexa da vertente. Esse tipo de curvatura está relacionado com a dinâmica dos processos de transporte e acumulação de água, sedimentos e matéria orgânica no solo e na superfície do terreno. Assim, as formas das vertentes poderão ser um indicativo da dinâmica erosiva da área abordada (VALERIANO, 2008b).

Os perfis convexos apresentam declividade acentuada nos trechos próximos a sua base, declividade menor em seus trechos médios, e declividade quase nula próxima ao topo. Já os perfis retilíneos, demostram o mesmo valor de declividade em todo o percurso da vertente. Não obstante, os perfis côncavos exibem declividade baixa próximo da base, declividades moderadas dos trechos centrais e declividades acentuadas próximas do topo (SILVA et al., 2007).

A curvatura horizontal expressa o formato da vertente quando observada em planta. Essa curvatura indica as áreas de escoamento superficial quanto ao sentido das linhas de fluxo, que podem ser classificadas quanto convergentes e divergentes. Dessa forma, as vertentes com curvatura horizontal convergente apresentam linhas de fluxo que convergem em um padrão semi-confinado, no qual tendem a apresentar maior velocidade de fluxo e competência de transporte. Em vertentes com essa geometria, o tempo de resistência do sedimento sobre a superfície do relevo é curto, o que favorece processos gravitacionais como o movimento de massa (BIGARELLA, 1994).

Segundo Valeriano e Albuquerque (2010), a medida da curvatura horizontal se baseia na mudança da orientação de vertentes em relação à distância horizontal, ao longo das curvas de nível. A curvatura horizontal das vertentes refere-se ao direcionamento dos fluxos de água orientados pela forma da vertente. Bloom (1996) definiu as encostas, com relação à curvatura horizontal em "coletoras de água" (vertentes convergentes) e "distribuidoras de água" (vertentes divergentes). 
Figura 3 - Formas de terreno de acordo com a curvatura vertical e curvatura horizontal

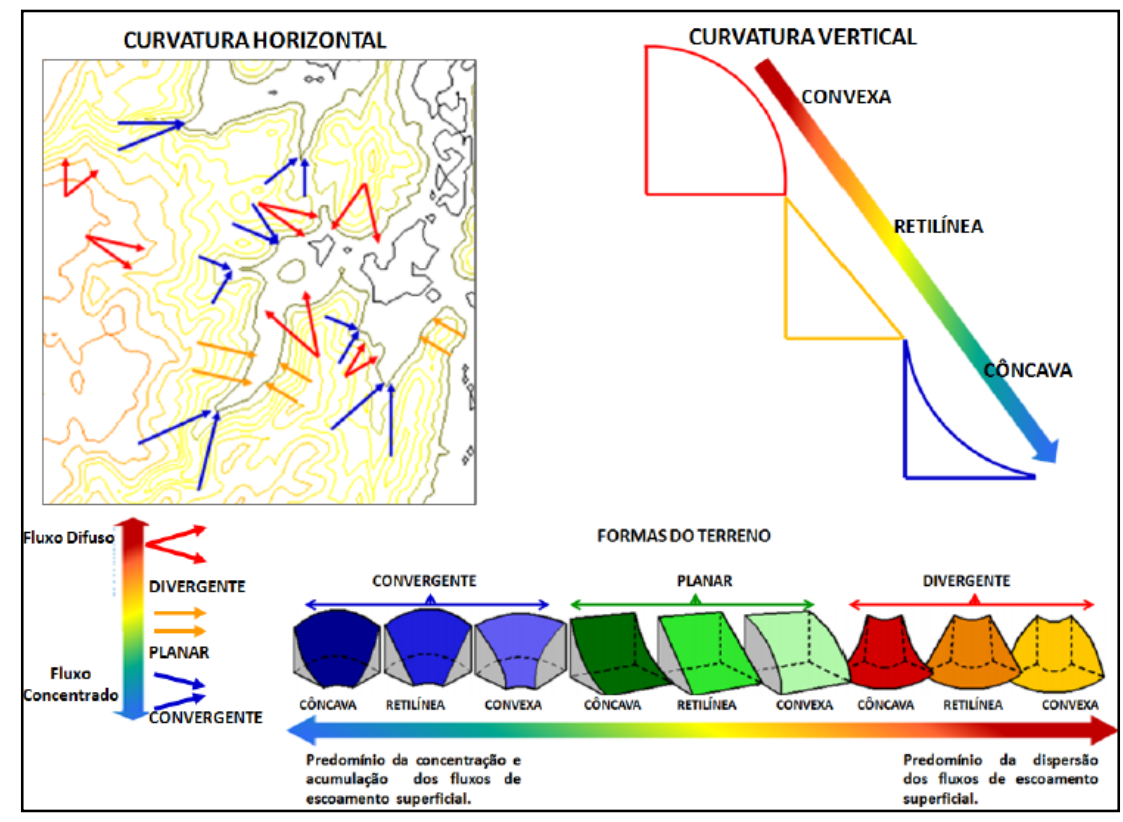

Fonte: Valeriano (2008a) adaptado por Silva Neto (2013)

Na dinâmica das encostas, as formas geométricas côncavas são zonas preferenciais para ocorrência de processos erosivos, em razão da convergência dos fluxos d'água, que aumenta a competência de transporte do fluxo e o colapso do substrato por pressão hidráulica, entre os materiais de diferentes características (SILVA et al., 2007). Já as formas do terreno convexas - divergentes, caracterizam-se como a classe de maior dispersão do escoamento superficial e menor concentração e acúmulo. Essas classes apresentam formas do terreno onde o escoamento superficial apresenta baixa capacidade de transporte e de remoção das partículas do solo, portanto, apresentam baixa vulnerabilidade à perda de solos (STABILE et al., 2013).

\subsubsection{Declividade}

A declividade é definida como o ângulo de inclinação (zenital) da superfície do terreno em relação à horizontal e que podem conter valores que variam de $0^{\circ}$ a $90^{\circ}$ ou em porcentagem de 0\% a infinito (VALERIANO, 2008 b). Usualmente, esse parâmetro, é definido em valores de porcentagem que atribui os valores da inclinação dos relevos em, (0-3\%) plano, (3-8\%) suave ondulado, (8-20\%) ondulado, (20-45\%) e forte ondulado, (45-75\%) montanhoso e (>75\%) escarpado (EMBRAPA, 1979). 
Esse parâmetro é o de maior associação aos deslizamentos, pois interfere diretamente na velocidade e competência de remobilização do substrato por fluxos superficiais (VALERIANO, 2008a; STABILE et al., 2013). O valor da inclinação de $30^{\circ}$ é como um patamar máximo, pois em valores acima, a possibilidade de deslizamentos tende a aumentar de maneira significativa (FREITAS et al., 2011).

\subsubsection{Hipsometria}

A hipsometria é um parâmetro que demostra os valores de altitude do relevo. Em relação aos valores de altitude e movimentos de massa, é importante salientar que, embora condicionante, não existem limites precisos para classificar o nível de suscetibilidade do terreno com relação a hipsometria (PINTO et al., 2013). Esse parâmetro exerce baixo impacto no desenvolvimento de fluxos gravitacionais, entretanto podem controlar a velocidade do escoamento superficial, o qual influencia diretamente na saturação do espaço poroso e na competência de transporte do fluxo, culminando na perda de solo e no transporte de sedimentos.

\section{MATERIAIS E MÉTODOS}

Para o estudo morfométrico da área, foram utilizados produtos de sensoriamento remoto e geoprocessamento que possibilitaram o mapeamento de regiões suscetíveis aos movimentos de massa. Os produtos de Sensoriamento Remoto utilizados neste trabalho, foram imagens SRTM (Shuttle Radar Topography Mission) fornecidas pelo INPE (Instituto Nacional de Pesquisas Espaciais), as quais foram posteriormente utilizadas para a geração de mapas temáticos e modelos digitais de elevação (MDE). Também foram adquiridos modelos digitais de variáveis geomorfométricas derivadas de imagens SRTM, desenvolvidas a partir do projeto TOPODATA-INPE. Os dados do projeto TOPODATA utilizados para esse estudo foram: declividade, curvatura vertical, curvatura horizontal e altitude. Estes dados são refinados da resolução espacial original de 3 arco-segundos ( 90m) para 1 arcosegundo ( $\sim 30 \mathrm{~m})$ por Krigagem (VALERIANO, 2008a). 
Os produtos do sensoriamento remoto foram inseridos em ambiente de SIG (Sistema de Informação Geográfica) utilizando o software QGis, para o mosaico e o recorte na área estudada, e posteriormente a geração de mapas temáticos na escala de 1:250.000. A escala escolhida tanto nos mapas temáticos quanto na carta final utiliza a escala de zoneamento regional de caráter informativo e consultivo, adequada para o planejamento estratégico regional do uso do território (FELL et al., 2008).

Foram considerados os atributos declividade, curvatura horizontal, curvatura vertical, hipsometria e densidade de lineamentos, para compreender o papel do meio físico sobre os fenômenos de deslizamento de massa, sem considerar a influência de fatores externos como atividades antrópicas e condições climáticas.

\subsection{Mapas temáticos}

O Mapa de declividade é uma ferramenta de grande importância para a análise do relevo, pois indica o nível de inclinação e influência da capacidade de infiltração ou escoamento do terreno. Esse mapa foi reclassificado quanto aos níveis de inclinação do terreno, conforme observado na Tabela 1, com o auxílio da ferramenta r.reclass do software QGis. As classes apresentadas foram agrupadas de acordo com as classes de porcentagem propostas pela EMBRAPA (1979).

Tabela 1 - Classificação de declividade utilizado para a classificação do mapa de declividade da área de estudo

\begin{tabular}{|c|c|c|}
\hline \multirow{7}{*}{ 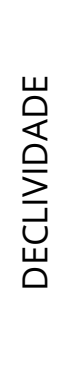 } & CLASSES & RELEVO \\
\hline & $0 \%-03 \%$ & Plano \\
\hline & $03 \%-08 \%$ & Suave Ondulado \\
\hline & $08 \%-20 \%$ & Ondulado \\
\hline & $20 \%-45 \%$ & Forte Ondulado \\
\hline & $45 \%-75 \%$ & Montanhoso \\
\hline & $>75 \%$ & Forte Montanhoso \\
\hline
\end{tabular}

Fonte: Adaptada da Embrapa, 1979

Os mapas de curvatura vertical e curvatura horizontal, foram preparados a partir do raster de 3 classes obtidos no projeto TOPODATA, e classificados quanto a geometria das vertentes de acordo com a classificação de VALERIANO (2008), utilizando a 
ferramenta simbologia do software QGis. No mapa de perfil vertical, os atributos considerados na análise foram as classes côncava, retilínea e convexa. Essas classes podem definir regiões de maior erosão e acumulação de sedimentos. Para o mapa de perfil horizontal, as classes obtidas são distribuídas quanto vertentes convergentes, planares e divergentes. Essas características indicam os padrões das linhas de fluxo de água e de sedimentos sobre o terreno, principalmente quanto aos padrões semiconfinados e desconfiados, divergência ou convergência de fluxo respectivamente (CARMO et al., 2016).

O mapa hipsométrico representa a altitude ideal do terreno e foi originado a partir da construção de um modelo digital de elevação (MDE). Esse produto foi gerado considerando cinco principais classes de elevação, representados por cotas que variam de $150 \mathrm{~m}$ a maior de $600 \mathrm{~m}$ e com equidistância de $150 \mathrm{~m}$. A divisão desse índice morfométrico em 5 classes equidistantes $(150 \mathrm{~m})$ foi escolhida a fim de diminuir a variância dentro das classes no resultado do cálculo de suscetibilidade. De forma geral, esta variável possui baixa influência no desenvolvimento de movimento de massas, discutido adiante, uma vez que não controla os padrões de escoamento superficial.

O mapa de densidade de lineamentos foi criado a partir de um modelo digital de elevação em conjunto a um modelo de superfície sombreada, onde se utilizou o software QGis para todo o processo de criação. A superfície de relevo sombreada foi gerada a partir do posicionamento do ângulo azimutal em dois principais quadrantes, $\mathrm{NE}$ e $\mathrm{SE}$, e mantendo o posicionamento zenital à $45^{\circ}$. Essa superfície ajudou a destacar áreas descontínuas do terreno, provavelmente marcadas por fratura e falhas e que, geralmente, coincidem com áreas de alto entalhamento fluvial. Uma vez vetorizados os lineamentos a partir dessas superfícies, os vetores foram transformados em pontos ao longo dos lineamentos utilizando a ferramenta Convert lines to points. Os pontos foram interpolados utilizando-se a ferramenta Kernel density estimation, gerando um mapa de calor que indicou as zonas com menor e maior concentração de lineamentos. O mapa foi classificado na ferramenta simbologia, de acordo com a densidade de lineamentos 
baixa, média, alta e muito alta, que indica uma diferença significativa entre as classes morfoestruturais propostas (SILVA e MAIA, 2017).

\subsection{Reclassificação de atributos de relevo}

O mapeamento das áreas com maiores suscetibilidades aos movimentos de massa foi determinada a partir de uma análise multicritério em ambiente SIG. O procedimento se baseia no mapeamento de variáveis por plano de informação e de cada um de seus componentes de legenda para a construção do resultado final (MOURA, 2007). Esse método realiza a análise de alternativas para a resolução de problema que utiliza vários critérios relacionados ao objeto de estudo, sendo possível identificar e hierarquizar as alternativas para o objetivo considerado (FRANCISCO et al., 2007).

Os mapas de características geomorfométricas do terreno foram reclassificados de acordo com o método Delphi, no qual atribui-se valores de 0 a 10 conforme sua potencial influência no desenvolvimento de eventos de movimento de massa. Em todos os mapas foi utilizado a ferramenta r.reclass no software QGis para reclassificá-los de acordo com o peso de casa variável. Esse método é comumente utilizado na área de Geociências como forma de ponderar uma escala de pesos para uma tomada de decisão (MEIJERING et al., 2015).

Os pesos de cada componente das variáveis foram definidos baseado na adaptação do método Delphi. Essa adaptação se baseou somente em bibliografias científicas (BIGARELLA, 1994; STABILE et al., 2013; VALERIANO e ALBUQUERQUE, 2010; BLOOM, 1996; CARMO et al., 2016; PINTO et al., 2013), e em conhecimentos préadquiridos quanto ao desenvolvimento de movimentação de massa. Cada componente foi reclassificada de acordo com a sua probabilidade de desencadear os movimentos de massa, no qual, valores próximos de 0 correspondem a menor influência do atributo no processo de movimento de massa. O inverso ocorre para valores próximos de 10 (Tabela 2). 
Tabela 2 - Pesos utilizados na operação de reclassificação das componentes de acordo com a sua probabilidade de desencadear os movimentos de massa.

\begin{tabular}{lclc}
\hline DECLIVIDADE (\%) & PESO & DENSIDADE DE LINEAMENTOS & PESO \\
\hline $0-03$ & 0 & Baixa & 0 \\
$03-08$ & 2 & Média & 1 \\
$08-20$ & 4 & Alta & 5 \\
$20-45$ & 6 & Muito alta & 10 \\
$45-75$ & 8 & & \\
$>75$ & 10 & & PESO \\
\hline HIPSOMETRIA & PESO & CURVATURA VERTICAL & 3 \\
\hline $0-150$ & 2 & Convexa & 6 \\
$150-300$ & 4 & Retilínea & 9 \\
$300-450$ & 6 & Côncava & PESO \\
\cline { 2 - 3 } $450-600$ & 8 & CURVATURA HORIZONTAL & 3 \\
\cline { 3 - 4 } 500 & 10 & Divergente & 6 \\
& & Planar & 9 \\
\hline
\end{tabular}

Fonte: autores (2020)

\subsection{Elaboração da carta de avaliação da suscetibilidade ambiental aos movimentos de massa}

Para a construção da carta de suscetibilidade ambiental aos movimentos de massa a partir de análise multicritério, cada mapa temático recebeu uma porcentagem de influência ao desenvolvimento de movimentos gravitacionais, o qual foi determinado de acordo com o método AHP (Analytical Hierarchy Process).

Esse método foi desenvolvido por SAATY (1977), que utiliza a técnica baseada na lógica de comparação pareada de critérios gerando uma matriz quadrada recíproca. 0 autor propôs uma escala de comparação com nove pontos que manifesta o grau de importância entre eles (Tabela 3), já que no método os diferentes critérios que influenciam a tomada de decisão são comparados dois a dois, sendo atribuído um valor de julgamento ao relacionamento entre eles, conforme uma escala pré-definida (Tabela 4).

A definição dos valores de importância entre os critérios determina os dados de entrada na matriz de comparação pareado (Tabela 5). Assim, o método gerou uma matriz quadrada de correlação pareada entre as variáveis, baseado no grau de importância de cada uma, assim observada na Tabela 6 . 
Tabela 3 - Escala de valores AHP para comparação pareada

\begin{tabular}{lcc}
\hline Intensidade de importância & Definição & Explicação \\
\hline 1 & Importância igual & Os dois fatores contribuem igualmente para o objeto. \\
3 & Importância moderada & A experiência e o julgamento favorecem levemente \\
5 & Importância essencial & Um fator sobre o outro \\
7 & Importância demonstrada claramente mais importante que o outro; & Um fator é muito fortemente favorecido; \\
9 & Importância extrema & A evidência que diferencia os fatores é de maior \\
& ordem possível. \\
$2,4,6,8$ & Valores intermediários & Quando se deseja um compromisso maior \\
\hline
\end{tabular}

Fonte: modificado de Saaty, 2008

Tabela 4 - Correlação pareada entre as variáveis geomorfométricas

\begin{tabular}{lcc}
\hline \multicolumn{2}{c}{ CORREAÇÃO PAREADA - AHP (Importância da coluna A em relação a coluna B) } \\
\hline \multicolumn{1}{c}{ A } & B & Importância \\
\hline Declividade & Curvatura vertical & 3 \\
Declividade & Densidade lineamento & 6 \\
Declividade & Curvatura horizontal & 8 \\
Declividade & Hipsometria & 9 \\
Curvatura vertical & Densidade lineamento & 3 \\
Curvatura vertical & Curvatura horizontal & 4 \\
Curvatura vertical & Hipsometria & 6 \\
Densidade lineamento & Curvatura horizontal & 2 \\
Densidade lineamento & Hipsometria & 4 \\
Curvatura horizontal & Hipsometria & 2 \\
\hline
\end{tabular}

Fonte: autores (2020)

Tabela 5 - Matriz quadrada de correlação pareada do método AHP

\begin{tabular}{lccccc}
\hline Critérios & $\mathbf{C}_{\mathbf{1}}$ & $\mathbf{C}_{\mathbf{2}}$ & $\mathbf{C}_{\mathbf{3}}$ & $\mathbf{C}_{\mathbf{4}}$ & $\mathbf{C}_{\mathbf{5}}$ \\
\hline $\mathrm{C}_{1}$ & 1 & $\mathrm{C}_{12}$ & $\mathrm{C}_{13}$ & $\mathrm{C}_{13}$ & $\mathrm{C}_{13}$ \\
$\mathrm{C}_{2}$ & $1 / \mathrm{C}_{12}$ & 1 & $\mathrm{C}_{23}$ & $\mathrm{C}_{23}$ & $\mathrm{C}_{23}$ \\
$\mathrm{C}_{3}$ & $1 / \mathrm{C}_{13}$ & $1 / \mathrm{C}_{23}$ & 1 & $\mathrm{C}_{34}$ & $\mathrm{C}_{34}$ \\
$\mathrm{C}_{4}$ & $1 / \mathrm{C}_{14}$ & $1 / \mathrm{C}_{24}$ & $1 / \mathrm{C}_{34}$ & 1 & $\mathrm{C}_{45}$ \\
$\mathrm{C}_{5}$ & $1 / \mathrm{C}_{15}$ & $1 / \mathrm{C}_{25}$ & $1 / \mathrm{C}_{35}$ & $1 / \mathrm{C}_{45}$ & 1 \\
\hline
\end{tabular}

Fonte: Adaptado de Saaty, 2008

Tabela 6 - Matriz quadrada de correlação pareada do método AHP com os valores atribuídos

\begin{tabular}{lccccc}
\hline Critérios & D & CV & DL & CH & H \\
\hline D & 1 & 3,00 & 6,00 & 8,00 & 9,00 \\
CV & 0,33 & 1 & 3,00 & 4,00 & 6,00 \\
DL & 0,17 & 0,33 & 1 & 2,00 & 4,00 \\
CH & 0,13 & 0,25 & 0,50 & 1 & 2,00 \\
H & 0,11 & 0,17 & 0,25 & 0,5 & 1 \\
\hline
\end{tabular}

Fonte: Adaptado de Saaty, 2008 
O autovetor (Av) é então calculado, a partir da média geométrica da linha $\left(\Sigma L_{n}\right)$ de cada variável. Em seguida é feita a normalização do autovetor (Av-normalizado), para que todos tenham a mesma ordem de grandeza (SAATY, 1991). A normalização de cada autovetor é

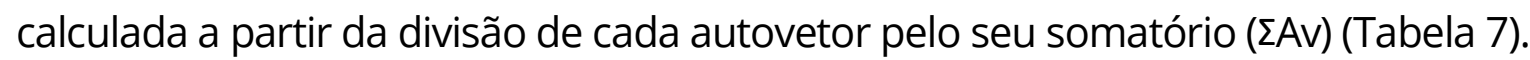

Tabela 7 - Matriz de normalização dos critérios analisados

\begin{tabular}{lccccccc}
\hline Critérios & $\mathbf{C}_{\mathbf{1}}$ & $\mathbf{C}_{\mathbf{2}}$ & $\mathbf{C}_{\mathbf{3}}$ & $\mathbf{C}_{\mathbf{4}}$ & $\mathbf{C}_{\mathbf{5}}$ & $\mathbf{A v}$ & Av normalizado \\
\hline $\mathrm{C}_{1}$ & 1 & $\mathrm{C}_{12}$ & $\mathrm{C}_{13}$ & $\mathrm{C}_{13}$ & $\mathrm{C}_{13}$ & $\Sigma \mathrm{L}_{1} / \mathrm{n}$ & $\mathrm{Av} v_{1} / \Sigma A v$ \\
$\mathrm{C}_{2}$ & $1 / \mathrm{C}_{12}$ & 1 & $\mathrm{C}_{23}$ & $\mathrm{C}_{23}$ & $\mathrm{C}_{23}$ & $\Sigma \mathrm{L}_{2} / \mathrm{n}$ & $\mathrm{Av} v_{2} / \Sigma \mathrm{Av}$ \\
$\mathrm{C}_{3}$ & $1 / \mathrm{C}_{13}$ & $1 / \mathrm{C}_{23}$ & 1 & $\mathrm{C}_{34}$ & $\mathrm{C}_{34}$ & $\Sigma \mathrm{L}_{3} / \mathrm{n}$ & $\mathrm{Av} v_{3} / \Sigma \mathrm{Av}$ \\
$\mathrm{C}_{4}$ & $1 / \mathrm{C}_{14}$ & $1 / \mathrm{C}_{24}$ & $1 / \mathrm{C}_{34}$ & 1 & $\mathrm{C}_{45}$ & $\Sigma \mathrm{L}_{4} / \mathrm{n}$ & $\mathrm{Av} v_{4} / \Sigma \mathrm{Av}$ \\
$\mathrm{C}_{5}$ & $1 / \mathrm{C}_{15}$ & $1 / \mathrm{C}_{25}$ & $1 / \mathrm{C}_{35}$ & $1 / \mathrm{C}_{45}$ & 1 & $\Sigma \mathrm{L}_{5} / \mathrm{n}$ & $\mathrm{Av} 5 / \Sigma \mathrm{Av}$ \\
$\Sigma \mathrm{C}$ & $\Sigma \mathrm{C}_{1}$ & $\Sigma \mathrm{C}_{2}$ & $\Sigma \mathrm{C}_{3}$ & $\Sigma \mathrm{C}_{4}$ & $\Sigma \mathrm{C}_{5}$ & $\Sigma \mathrm{Av}$ & $100 \%$ \\
\hline
\end{tabular}

Fonte: Adaptado de Saaty, 2008

Na matriz de ponderação foram empregues os valores de cada variável para serem normalizados (Tabela 8). A normalização feita a partir da divisão de autovetor pelo seu somatório gerou o valor influência de cada variável geomorfométrica (Tabela 9). Com esse dado, pode-se definir a média ponderada utilizada para a álgebra da carta final. Neste trabalho, foram utilizados cinco critérios: declividade, curvatura vertical, curvatura horizontal, densidade de lineamentos e hipsometria.

Tabela 8 - Matriz de normalização dos critérios analisados

\begin{tabular}{lccccccc}
\hline Critérios & D & CV & DL & CH & H & Av & Av-normalizado \\
\hline D & 1 & 3,00 & 6,00 & 8,00 & 9,00 & 4,19 & $54,25 \%$ \\
CV & 0,33 & 1 & 3,00 & 4,00 & 6,00 & 1,89 & $24,43 \%$ \\
DL & 0,17 & 0,33 & 1 & 2,00 & 4,00 & 0,85 & $11,00 \%$ \\
CH & 0,13 & 0,25 & 0,5 & 1 & 2,00 & 0,50 & $6,47 \%$ \\
H & 0,11 & 0,17 & 0,25 & 0,5 & 1 & 0,30 & $3,84 \%$ \\
Soma & 1,74 & 4,75 & 10,75 & 15,5 & 22 & 7,73 & $100 \%$ \\
\hline
\end{tabular}

Fonte: autores (2020)

Tabela 9 - Influências (\%) utilizadas na operação de álgebra de mapas para calcular a carta final

\begin{tabular}{lccc}
\hline \multicolumn{1}{c}{ Categoria } & Símbolo & Influência & Classificação \\
\hline Declividade & $\mathrm{D}$ & $54,25 \%$ & 1 \\
Curvatura vertical & $\mathrm{CV}$ & $24,43 \%$ & 2 \\
Densidade de lineamentos & $\mathrm{DL}$ & $11,00 \%$ & 3 \\
Curvatura horizontal & $\mathrm{CH}$ & $6,47 \%$ & 4 \\
Hipsometria & $\mathrm{H}$ & $3,84 \%$ & 5 \\
\hline
\end{tabular}

Fonte: autores (2020) 
O valor gerado indicou que a variável de maior influência em porcentagem (\%) é a declividade. Essa variável sofre influência do ângulo de atrito e do mergulho nas descontinuidades rochosas com controle estrutural, e influência da coesão do maciço atribuído ao ângulo de atrito interno quando não há controle estrutural (FERNANDES e AMARAL, 1996). A declividade possui forte relação com o desenvolvimento de fluxos gravitacionais, pois determina o nível de inclinação da encosta, definindo assim o grau de deslizamento por processos superficiais ao longo das vertentes (PRADHAN, 2010).

Para certificar a consistência do resultado obtido, é preciso determinar a razão de consistência (RC) através da seguinte Equação (1):

$R C=\frac{I C}{I R}$

Em que:

$I C=\frac{(\lambda-\text { máx. }-\mathrm{n})}{(\mathrm{n}-1)}$, onde: $\lambda-\operatorname{máx}=[\Sigma \mathrm{Cn}] \times[\mathrm{AV}-$ normalizado $]$

Sendo:

IC= índice de Consistência;

IR= índice Randômico;

$\mathrm{n}=$ número de ordem da matriz;

$\lambda$-máx. = autovalor;

$\Sigma \mathrm{Cn}$ = somatório de cada coluna das variáveis;

AV-normalizado = autovetor-normalizado;

O índice Randômico é um valor tabelado, que varia de acordo com a ordem da matriz (Tabela 10)

Tabela 10 - Valores de IR em função da ordem da matriz quadrada

\begin{tabular}{cccccccccccccccc}
\hline $\mathbf{N}$ & $\mathbf{1}$ & $\mathbf{2}$ & $\mathbf{3}$ & $\mathbf{4}$ & $\mathbf{5}$ & $\mathbf{6}$ & $\mathbf{7}$ & $\mathbf{8}$ & $\mathbf{9}$ & $\mathbf{1 0}$ & $\mathbf{1 1}$ & $\mathbf{1 2}$ & $\mathbf{1 3}$ & $\mathbf{1 4}$ & $\mathbf{1 5}$ \\
\hline $\mathrm{IR}$ & 0 & 0 & 0,53 & 0,89 & 1,12 & 1,25 & 1,35 & 1,40 & 1,45 & 1,49 & 1,52 & 1,54 & 1,56 & 1,58 & 1,59 \\
\hline
\end{tabular}

Fonte: adaptado de Saaty, 2008

A razão de consistência $(R C=I C / I R)$ deve ser menor que 0,10 para que as matrizes sejam aceitáveis. No entanto, valores superiores que 0,10 não são adequados, ou seja, a 
matriz não está apta para ser utilizada na álgebra de mapas e deve-se revisar os julgamentos paritários.

A coerência dos resultados foi calculada em Razão de Consistência (RC), onde gerou o valor de 0,03 atendendo o requisito de que o RC deve ser inferior a 0,10 para considerá-lo adequado na álgebra de mapas (SAATY, 1991). O valor foi adquirido segundo a Equação (2), que utilizou os valores da Tabela 11.

$R C=\frac{I C}{I R}$

Onde:

$\lambda$-máx. $=5,13$;

$\mathrm{n}=5$;

IC $=(5,13-5) /(5-1)$;

$\mathrm{IC}=0,03$;

$\mathrm{IR}=1,12$.

$R C=0,03$

Tabela 11 - Valor do autovalor para cálculo o índice de consistência

\begin{tabular}{lcccccc}
\hline Critérios & D & CV & DL & CH & H & TOTAL \\
\hline Autovalor & 0,94 & 1,16 & 1,18 & 1,00 & 0,85 & 5,13 \\
\hline
\end{tabular}

Fonte: autores (2020)

Dentro dessa análise, permitiu- se utilizar a equação da Média Ponderada (3) que possibilita fazer a álgebra de mapas a partir dos pesos gerados pelos métodos de ponderação que irão influenciar no resultado final.

$C A S A M M=(v 1 * w i 1)+(v 2 * w i 2)+(v n * w i n)$

Em que:

CASAMM: carta de avaliação da suscetibilidade ambiental aos movimentos de massa; $v$ = variáveis morfométricas ponderadas;

wi = peso de influência.

Substituindo os valores no cálculo da média ponderada, tem-se:

$C A S A M M=(D * 0,54)+(C V * 0,24)+(D L * 0,11)+(C H * 0,06)+(H * 0,04)$ 
Em que:

D: Declividade;

CV: Curvatura Vertical;

DL: Declividade Linear;

$\mathrm{CH}$ : Curvatura Horizontal;

H: Hipsometria.

A álgebra de mapas foi aplicada a partir da equação da média ponderada utilizando os pesos de influência de cada mapa. Utilizou-se a ferramenta Raster Calculator no software QGis que agrupou os mapas de acordo com o seu valor, e a soma de todas as variáveis resultou na carta final de suscetibilidade (Figura 4).

Figura 4 - Cruzamento de variáveis para a realização da carta final

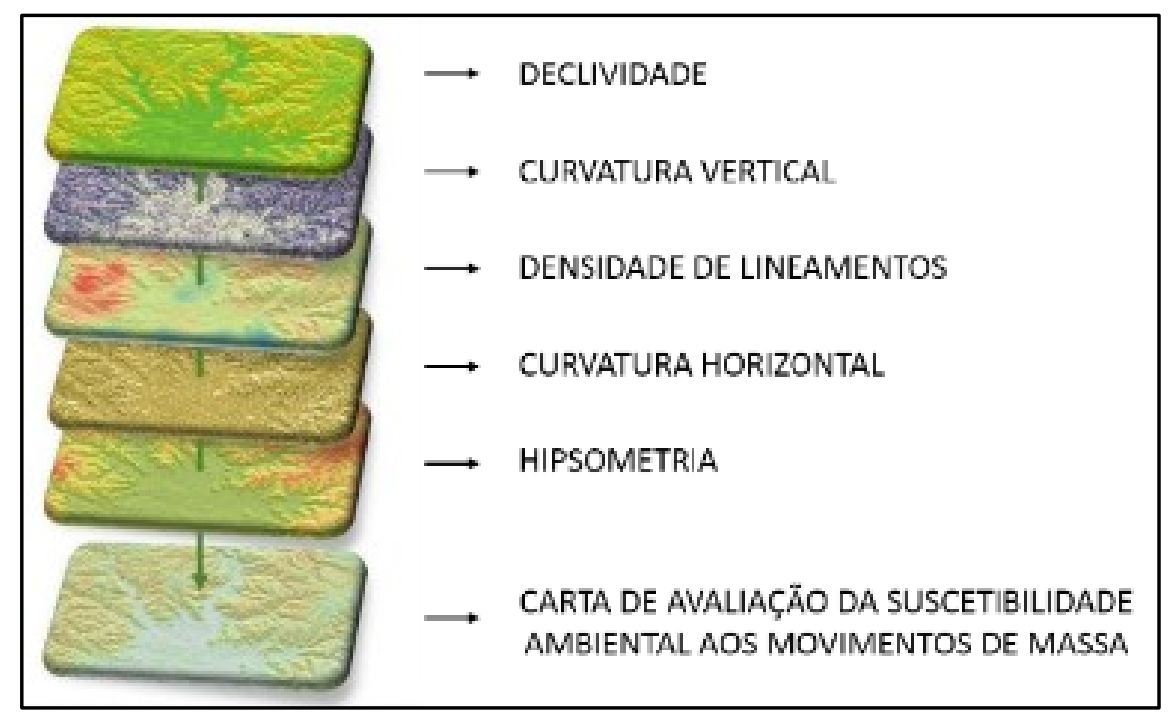

Fonte: autores (2020)

A carta de avaliação da suscetibilidade ambiental aos movimentos de massa da área em estudo, foi gerada a partir do cruzamento dos pesos de influência das variáveis utilizando a equação da média ponderada. A mesma foi gerada e representada na escala 1:250.000 e Datum Sirgas 2000. O procedimento resultou de um raster contendo cinco classes (Muito Baixo, Baixo, Médio, Alto, Muito Alto), que correspondem a níveis de suscetibilidade. A classificação foi determinada de maneira estatística por meio da quebra natural, onde os intervalos são normatizados para diminuir a variância dentro das classes (CARMO et. al, 2015). 


\section{RESULTADOS E DISCUSSÕES}

Os métodos utilizados, tanto para a construção de mapas temáticos quanto para a carta final foram aplicados com o intuito de zonear áreas de suscetibilidade aos movimentos de massa na área em estudo. A utilização das imagens em conjunto com SIG, resultou em mapas temáticos das variáveis (i) declividade, (ii) curvatura vertical, (iii) curvatura horizontal, (iv) densidade de lineamentos e (v) hipsometria, demostrados a seguir de forma hierárquica, de acordo com sua influência no desenvolvimento de eventos de movimentos de massa:

\subsection{Mapas temáticos}

O mapa de declividade da área de estudo foi classificado com base em uma adaptação do estudo da Embrapa (1979) (Figura 5a). Essa classificação permite a observação de relevos planos (0-3\%) a ondulados (8-20\%) na região central e no topo das áreas com maiores altitudes. Já os relevos de fortemente-ondulado (20-45\%) a montanhoso (45-75\%) são observados em grande parte das encostas, acompanhados por relevos forte-montanhoso (>75\%) que ocorrem nas regiões mais próximas do topo das vertentes. Dessa forma, é possível observar que as regiões próximas de topo de vertentes são áreas que em conjunto a outras variáveis podem culminar ao deslizamento de massa.

O mapa de curvatura vertical foi obtido e classificado em vertentes de geometria côncava, retilínea e convexa, de acordo com Valeriano (2008a) (Figura 5b). Na área de estudo, os perfis côncavos são comumente localizados na base das vertentes e próximos ao topo encontram-se os perfis convexos. Por sua vez, a zona central da região é predominantemente retilínea, o que é esperado nos processos erosivos de origem de vertentes sem perturbações tectônicas (KELLER e PINTER, 2002). A região mais próxima ao topo das vertentes apresenta perfis convexos, o que torna esses locais mais suscetíveis aos movimentos de massa, já que são áreas dominadas por rastejamento e predomínio de escoamento superficial (BLOOM, 1996).

Como a distribuição litoestratigráficas das vertentes é composta principalmente por rochas vulcânicas do Grupo Serra Geral, nesse trabalho considerou-se uma região isotrópica 
quanto ao comportamento reológico das rochas. $\mathrm{Na}$ interface das vertentes, o atributo solo também não foi considerado, a julgar pela espessura e baixo desenvolvimento de perfis de solos coluviais nessa região, caracterizados como neossolos litólicos (LEMOS, 1973).

Como a coleta de medidas estruturais em rocha para um mapeamento na escala de trabalho sugerida é economicamente inviável, considerou-se a distribuições de grandes lineamentos estruturais. Ao atribuir essa variável no cálculo de suscetibilidade de movimentação de massa, entende-se que essas estruturas respondem a uma deformação rúptil posterior a construção desses compartimentos rochosos. No qual, variavelmente, pode refletir no grau de faturamento da rocha em escala local. Dessa maneira, áreas com alta densidade de lineamento sugerem a presença de massa rochosa com maior distribuição de famílias de fraturas o que diminui sua resistência (DONATI e TURRINI, 2002), e por consequência desenvolve maior suscetibilidade.

Nesse trabalho, os lineamentos foram apresentados pela sua concentração em determinada área, ou seja, a densidade de lineamentos (Figura 5c). A região central não apresenta grande densidade de lineamentos, isto é, as rochas que constituem o local são estruturalmente mais homogêneas. Todavia, as regiões periféricas de alta altitude exibem maior grau de fraturamento que interferem na resistência dos maciços rochosos e, consequentemente, facilita o processo de movimentação de massa.

A classificação da curvatura horizontal apresenta três tipos: convergente, divergente e planar. Essas curvaturas se associam aos direcionamentos de fluxos de água, podendo ser coletoras de água (convergente) ou distribuidoras de água (divergentes) (BLOOM, 1996). No mapa as curvaturas horizontais que maior se concentram são as de curvatura convergente, que coincidem com vales de rios de menor hierarquia e alto entalhamento fluvial (Figura $5 d$ ).

O mapa de hipsometria demostra a altimetria da região, indicando as cotas existentes (Figura 5e). A partir dele é possível observar os diferentes comportamentos altimétricos da superfície do terreno, evidenciando a diferença de altitude entre a interface do planalto meridional e a depressão central na região de estudo. A variável hipsométrica desempenha baixo impacto no desenvolvimento de fluxos gravitacionais, no entanto, em conjunto com outras variáveis, ela pode intensificar a velocidade e intensidade dos movimentos originados (ARAÚJO, 2004). 
Figura 5 - Mapas temáticos de variáveis morfométrica para a área de estudo: a) Mapa de declividade; b) Mapa de curvatura vertical; c) Mapa de densidade de lineamentos; d) Mapa de curvatura horizontal; e) Mapa hipsométrico

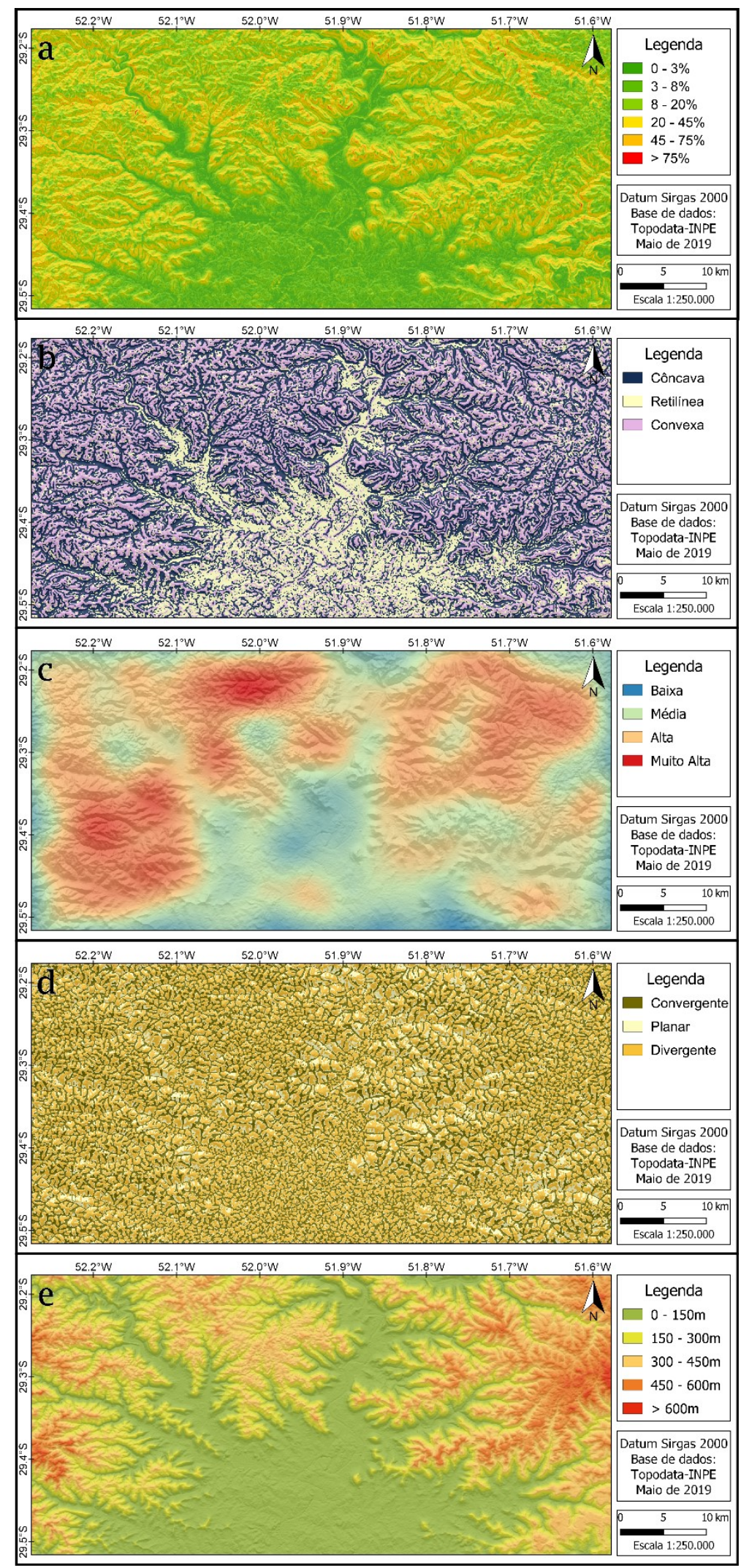

Fonte: autores (2020) 


\subsection{Carta de Suscetibilidade aos movimentos de massa}

A carta de avaliação da suscetibilidade ambiental aos movimentos de massa (CASAMM) é o produto final, resultado da associação das variáveis declividade, curvatura vertical, densidade de lineamentos, curvatura horizontal e hipsometria. Essas variáveis morfométricas são as características naturais do substrato com maior relevância na análise de suscetibilidade aos movimentos de massa, pois consideram as morfoesculturas presentes na interface das encostas.

A CASAMM apresenta cinco classes que demonstram o grau de suscetibilidade aos movimentos de massa na região, classificados em muito baixo, baixo, médio, alto e muito alto (Figura 6). Essa classificação demostra áreas restritas à ocupação e desenvolvimento socioeconômicos, uma vez que apresentem zonas de índice suscetível alto a muito alto. A carta sugere os padrões e os tipos de processos geomorfológicos existentes na área de estudo. Pode-se notar encostas íngremes, onde esses processos podem ser desenvolvidos tanto de forma branda quanto de forma mais agressiva. Do mesmo modo, as áreas definidas pelos índices mais baixos podem ser locais favoráveis ao desenvolvimento de uso e ocupação territorial. É válido lembrar, que as regiões já ocupadas, necessitam ser monitoradas e gerenciadas de acordo com o índice de suscetibilidade que apresentam. Assim sendo, a carta resultante exerce um papel fundamental na administração e gestão pública dos locais já ocupados e no planejamento de futuras ocupações para um desenvolvimento bem sucedido na região.

Na carta é observado que a região de interface entre a depressão central e o planalto meridional apresenta alto grau de suscetibilidade na maior parte das vertentes, em função da alta declividade presente nestes locais. As regiões com maiores altitudes não necessariamente manifestam maior índice suscetível, já que podem configurar áreas altas e de topos mais planos. Dessa forma, confirma a hierarquia das variáveis morfométricas estipuladas pelo método AHP, que indica a declividade e curvatura 
vertical como os principais fatores de controle morfométricos no desenvolvimento de eventos de movimentação de massa.

A declividade é a variável com maior índice de influência em porcentagem (\%) entre as cinco variáveis, já que indica o nível de inclinação, como já foi citado. Portanto, essas regiões são associadas com encostas íngremes, o que pode proporcionar o desencadeamento de movimentos de massas mais moderados ou mais violentos como os deslizamentos, corridas de lama e queda de blocos (CARMO et al., 2016). Em contrapartida, a hipsometria gerou menor índice de influência em porcentagem (\%) uma vez que caracteriza somente a altitude do terreno. Nessa análise os fatores antrópicos como, clima, vegetação e ocupação territorial não foram utilizados. No entanto são fatores que intensificam e/ou aceleram os processos naturais de movimentação de massa.

Assim como o esperado, a região central da área tem o grau suscetível mais baixo em relação aos movimentos de massa, principalmente por apresentar uma baixa declividade e altitude. No entanto, locais próximos às vertentes, podem ser considerados áreas de maior convergência de materiais de movimentos de massa ativos (em pequena escala). Também, os movimentos tipo creep (movimentos lentos e contínuos) podem se desenvolver nessa região, de modo que estão relacionados a baixa declividade (FREITAS et al., 2011). As áreas próximas as grandes cristas também não apresentam zonas de alta suscetibilidade, assim como as zonas de baixa altitude onde se concentram os grandes centros populacionais como Lajeado e Estrela. No entanto, regiões com altitudes entre 300 a $600 \mathrm{~m}$ se concentram as maiores áreas suscetíveis, pois apresentam curvaturas côncavas que convergem fluxos superficiais, proporcionando fluxos confinados e, consequentemente, o desenvolvimento de alta pressão hidráulica sob o substrato. Esses condicionantes, aumentam a suscetibilidade de gerando da ocorrência de fluxos gravitacionais. 
Figura 6 - Carta de avaliação da suscetibilidade ambiental aos movimentos de massa

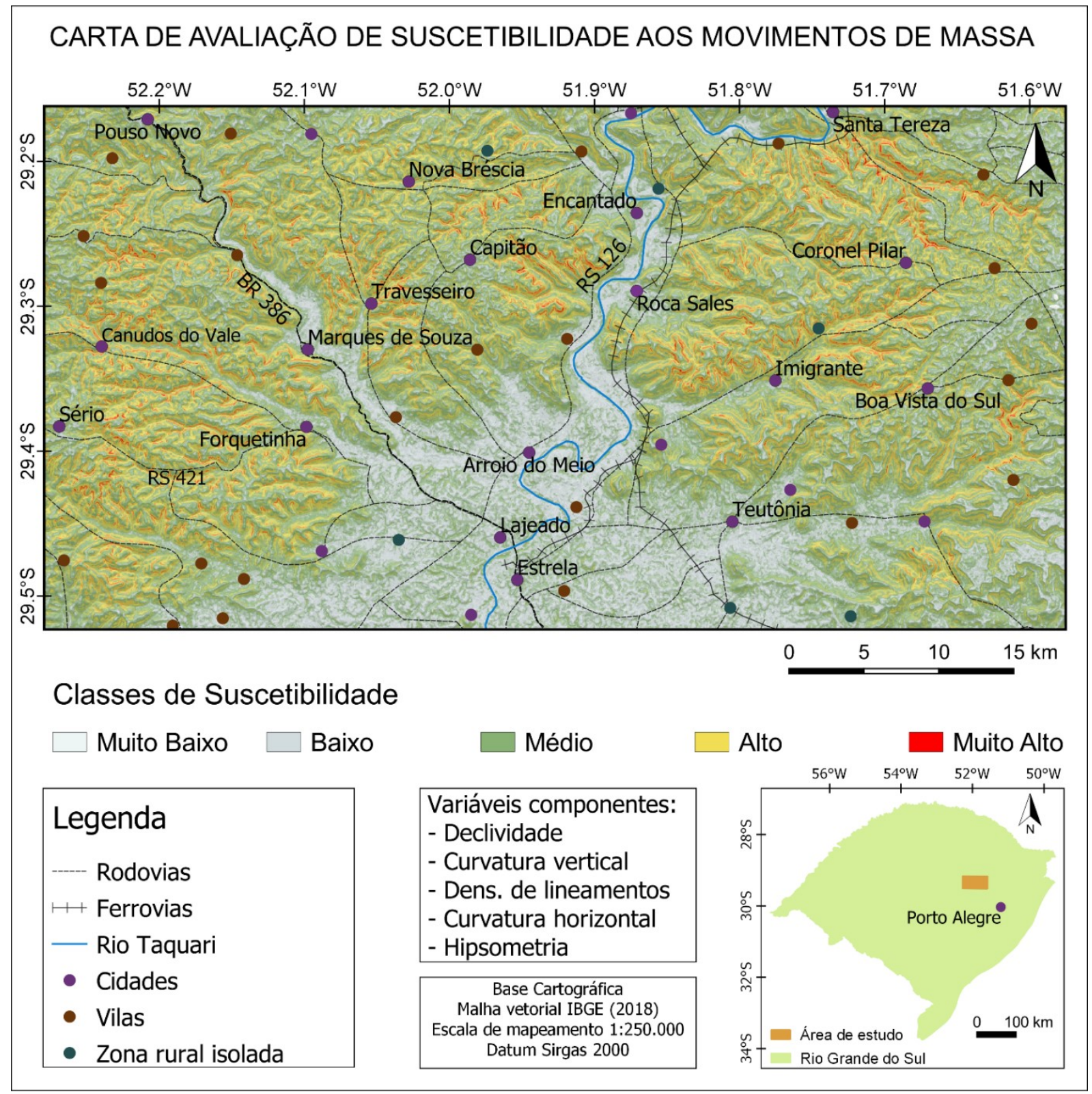

Fonte: autores (2020)

As populações menores podem ser encontradas em regiões de suscetibilidade mais elevada, o que sugere o desenvolvimento de um possível risco nessas áreas. Entre elas podemos destacar Santa Teresa, Coronel Pilar, Roca Sales, Imigrante, Nova Bréscia, Pouso Novo, Marques de Souza e Travesseiro, concentrados em regiões contiguas às zonas de elevados índices de suscetibilidade. Este alto índice pode estar relacionado à declividade do terreno presente nessas áreas, majoritariamente acima de 30\%. A geometria das vertentes também pode contribuir para esse resultado, caracterizadas, em sua grande maioria, por formas curvaturas côncavas-convergentes, as quais 
favorecem fluxos hidráulicos confinados e de alta viscosidade. Essas áreas também se concentram em zonas com alta densidade de lineamentos, o que demostra um terreno mais fraturado e suscetível ao colapso por gravidade.

As vias de acesso rodoviária e ferroviária também percorrem por regiões contidas ou adjacentes a zonas de alta suscetibilidade, principalmente no entorno de Boa Vista do Sul, Capitão, Marques de Souza, Pouso Novo e Encantado. Destacam-se as rodovias RS 130 (trecho entre Capitão e Encantado), RS 421 (trecho entre Forquetinha e Sério), BR 386 (entre Marques de Souza e Pouso Novo), e na via de acesso entre Santa Tereza e Coronel Pilar, as quais se concentram em áreas próximas à encosta com alto adensamento de lineamentos, o que sugere materiais fraturados. Esse fator em conjunto como a geometria das vertentes côncava e declividades acima de 20\%, proporcionou o alto índice de suscetibilidade para esse setor. Essas características, portanto, contribuem para a maior ocorrência de fluxos concentrados e/ou em um padrão semi-confinado, o que estimula o colapso do substrato.

No geral, as pequenas cidades estão inseridas na interface de maior grau suscetível, as quais possuem sua economia baseada na agroindústria e na agricultura familiar. Além disso, em muitas rodovias importantes para região há encostas com índice muito alto, como a rodovia que liga Forquetinha a Marques de Souza. Dessa forma, o possível desenvolvimento de eventos de movimentação de massa poderiam gerar danos socioeconômicos notáveis nestas áreas.

Ainda que alguns centros populacionais sejam caracterizados por uma baixa população, é notório que a região vem se expandindo socioeconomicamente. No entanto, grande parte desses centros possuem zonas onde o grau de suscetibilidade é elevado. Sendo assim, a carta de avaliação de suscetibilidade aos movimentos de massa nos permite entender esses fenômenos e localizá-los para aplicar no gerenciamento do território. Os locais que apresentam elevado grau suscetível, quando próximos a rodovias ou áreas habitadas, devem ser estudados a partir de mapas geotécnicos ou melhor entendimento de mecânica de rochas com escalas mais locais. Um estudo mais detalhado dessas áreas alvos de movimentação de massa poderá prevenir ou minimizar os danos socioeconômicos que essas cidades podem sofrer. 


\section{CONSIDERAÇÕES FINAIS}

O estudo retratou o uso de produtos de Sensoriamento Remoto em conjunto às técnicas de geoprocessamento no auxílio do zoneamento de áreas suscetíveis aos movimentos de massa. Para isso foi necessário integralizar mapas temáticos, junto ao software QGis, para a confecção de uma carta temática a partir de métodos de ponderação Delphi e AHP. Essa carta foi o produto dos critérios de declividade, curvatura vertical, curvatura horizontal, densidade de lineamentos e hipsometria que são os principais parâmetros morfométricos utilizados na álgebra de mapas para identificação e zoneamento de áreas suscetíveis ao deslizamento de massa na área de estudo.

A Carta de Avaliação da Suscetibilidade Ambiental aos Movimentos de Massa mostrou ser um precípuo recurso para gestão ambiental e planejamento territorial, que poderá auxiliar no estudo mais aprofundado de áreas chaves. Além de ser uma ferramenta para a indicação de áreas mais favoráveis para ocupação urbana e construções civis, a carta também aponta as áreas que devem ser evitadas em projetos de desenvolvimento socioeconômico. $\mathrm{Na}$ área de estudo, a carta será um subsídio para prevenção, monitoramento e correção dos processos suscetíveis atuantes no território que podem ser melhor entendidos com estudos localizados de estabilidade de taludes.

\section{AGRADECIMENTOS}

Os autores agradecem a Universidade Federal de Pelotas pelo apoio institucional e laboratorial durante o desenvolvimento desse trabalho. Também agradecem aos revisores anônimos que forneceram recomendações úteis para a melhora deste artigo.

\section{REFERÊNCIAS}

ARAÚJO PC. Análise da suscetibilidade a escorregamentos: uma abordagem probalísitca [thesis]. Rio Claro: Instituto de Geociências e Ciências Exatas/Unesp; 2004.187p.

BECKER ELS, NUNES MP. Relevo do Rio Grande do Sul, Brasil, e sua representação em maquete.

Revista Percurso. 2012;4(2):113-132. 
BIGARELLA J, BECKER RD, SANTOS GF, HERRMANN MLP, CARVALHO SMC, MENDONÇA M. Estrutura e origem das paisagens tropicais e subtropicais. 3. ed. Florianópolis: Editora da UFSC; 1994.

BITAR OY. Cartas de suscetibilidade a movimentos gravitacionais de massa e inundações: 1: 25.000: nota técnica explicativa. São Paulo: IPT; CPRM; 2014.

BLOOM AL. Superfície da terra. São Paulo: Edgard Blucher; 1996.

BRASIL. Lei $\mathbf{n}^{\circ} \mathbf{1 2 . 6 0 8}$ de 10 de Abril de 2012 [Internet]: Política Nacional de Proteção e Defesa Civil (PNPDEC) (BR) [cited may 19].Available from: http://www.planalto.gov.br/ccivil_03/_Ato20112014/2012/Lei L,12608.

CARMO AM, SOUTO MVS, DUARTE CR, MESQUITA AF. ANÁLISE de Risco Ambiental à Erosão Gerada a partir de produtos de sensores remotos: MDE Topodata e Landsat 8. In: Anais XVII Simpósio Brasileiro de Sensoriamento Remoto - SBSR;2015 abr 25-29; João Pessoa, Brasil. p.5927-5934.

CARMO AM, SOUTO MVS, DUART CR, LOPES PS, SABADIA JAB. Avaliação de susceptibilidade de risco à erosão, utilizando as variáveis morfométricas, para as serras da porção sul do maciço central do Ceará. Revista Brasileira de Cartografia, 2016;68(9):1787-1804.

DONATI L, TURRINI MC. An objective method to rank the importance of the factors predisposing to landslides with the GIS methodology: application to an area of the Apennines (Valnerina; Perugia, Italy). Engineering Geology; 2002; 63(3-4):277-289.

EMPRESA BRASILEIRA DE PESQUISA AGROPECUÁRIA. EMBRAPA. Serviço Nacional de Levantamento e Conservação de Solos. Súmula da 10. Reunião Técnica de Levantamento de Solos. Rio de Janeiro (Brasil), 1979. 83p.

FELL R, COROMINAS J, BONNARD C, CASCINI L, LEROI E, SAVAGE W Z. Guidelines for landslide susceptibility, hazard and risk zoning for land-use planning. Engineering Geology. 2008;102(34):99-111.

FERNANDES NF, AMARAL. CP do. Movimentos de massa: uma abordagem geológicogeomorfológica. Geomorfologia e Meio Ambiente. Bertrand Brasil. 1996:123-194.

FRANCISCO CES, COELHO RM, TORRES RB, ADAMI SF. Espacialização de analise multicritério em SIG: prioridades para recuperação de Áreas de Preservação Permanente. In: Anais XIII Simpósio Brasileiro de Sensoriamento Remoto; 2007. p .2643-2650.

FREITAS CGL, et al. Procedimentos na elaboração da carta geotécnica de planejamento do município de Cunha, SP. In: 13. Congresso Brasileiro de Geologia de Engenharia e Ambiental - 13. CBGE; 2011 nov; São Paulo, Brasil.

HOFF R, DUCATI JR, COUTINHO ALS, TONIETTO J. Uso de imagens orbitais no estudo das características espectrais das rochas para o estabelecimento de critérios para uma indicação de 
procedência vinícola na região de Pinto Bandeira, Bento Gonçalves, RS, Brasil. In Embrapa Uva e Vinho (ALICE). In: Simpósio Brasileiro de Sensoriamento Remoto; 2007; Florianópolis, Brasil.

HOFFMANN GR, AREND LM, SILVEIRA JCBD, BELLOMO HR, NUNES JLM. Rio Grande do Sul: aspectos da geografia. Porto Alegre: Martins Livreiro; 1992.

INSTITUTO BRASILEIRO DE GEOGRAFIA E ESTATÍSTICA. IBGE [Internet] (BR) [cited 2019]. Available from: http://www.ibge.gov.br/pt/inicio.html.

INSTITUTO BRASILEIRO DE GEOGRAFIA E ESTATÍSTICA. IBGE [Internet] (BR) [cited 2017]. Available from: https://censos.ibge.gov.br/agro/2017/.

INSTITUTO BRASILEIRO DE GEOGRAFIA ESTATÍSTICA. IBGE. Manual técnico de geomorfologia; 2009.

KAWABATA D, BANDIBAS J. Landslide susceptibility mapping using geological data, a DEM from ASTER images and an Artificial Neural Network (ANN). Geomorphology. 2009;113(1-2):97-109.

KELLER EA, PINTER N. Active Tectonics: Active tectonics: earthqakes, uplift, and landscape. New Jersey, Prentice Hall; 2002.

LEMOS RC. Levantamento de reconhecimento dos solos do Estado do Rio Grande do Sul. Embrapa Solos-Séries anteriores (INFOTECA-E); 1973.

MACHADO NT, SCHNEIDER P, FIEGENBAUM J, WELP M. A ocupação Guarani no Vale do Taquari/RS: notas prévias sobre as pesquisas arqueológicas. Revista Cadernos do Ceom. 2014;19(24):123-136.

MEIJERING JV, TOBI H, VAN DEN BRINK A, MORRIS F, BRUNS D. Exploring research priorities in landscape architecture: An international Delphi study. Landscape and Urban Planning. 2015;(137):85-94.

MOREIRA I. O espaço rio-grandense. São Paulo: Ática; 2003.

MOURA ACM. Reflexões metodológicas como subsídio para estudos ambientais baseados em Análise de Multicritérios. In: Anais do XII Simpósio Brasileiro de Sensoriamento Remoto; 2007 abr 21-26; Florianópolis, Brasil. p. 2899-2906.

O'LEARY DW, FRIEDMAN JD, POHN HA. Lineament, linear, lineation: some proposed new standards for old terms. Geological Society of America Bulletin. 1976;87(10):1463-1469.

OZDEMIR A. GIS-based groundwater spring potential mapping in the Sultan Mountains (Konya, Turkey) using frequency ratio, weights of evidence and logistic regression methods and their comparison. Journal of Hydrology. 2011;411(3-4):290-308.

PINTO RC, PASSOS E, CANEPARO SC. Considerações a respeito dos condicionantes utilizados em pesquisas envolvendo movimentos de massa. Revista do Programa de Pós-Graduação em Geografia. 2013;5(1):102-124. 
PRADHAN B. Remote sensing and GIS-based landslide hazard analysis and cross-validation using multivariate logistic regression model on three test areas in Malaysia. Advances in Space Research. 2010;45(10):1244-1256.

RITTER DF, KOCHEL RC, MILLER J R. Process geomorphology; 2002.

SAATY TL. A scaling method for priorities in hierarchical structures. Journal of mathematical psychology. 1977;15(3):234-281.

SAATY TL. Decision making with the analytic hierarchy process. International journal of services sciences. 2008;1(1):83-98.

SAATY TL, VARGAS LG. Prediction, projection, and forecasting: applications of the analytic hierarchy process in economics, finance, politics, games, and sports. Boston (USA): Kluwer Academic Publishers; 1991.

SILVA NETO JCA. Avaliação da vulnerabilidade à perda de solos na bacia do rio Salobra, MS, com base nas formas do terreno. Geografia (Londrina). 2013;22(1):05-25.

SILVA MB, MAIA RP. Caracterização morfoestrutural do alto curso da bacia hidrográfica do rio Jaguaribe, Ceará-Brasil. Revista Brasileira de Geomorfologia. 2017;18(3):637-655.

SILVA AM, SCHULZ HE, CAMARGO PB. Hidrossedimentologia em bacias hidrográficas. In: Erosão e Hidrossedimentologia em Bacias Hidrográficas. São Carlos: RIMA; 2007. p. 105-135.

STABILE RA, FERREIRA AL, CARVALHO AM, SIQUEIRA AG, BITAR OY. Análise de fatores condicionantes de instabilizações em encostas como subsídio para a modelagem estatística da suscetibilidade a deslizamentos. In: 14. Congresso Brasileiro de Geologia de Engenharia e Ambiental; 2013.

VALERIANO MM. Dados topográficos. In: FLORENZANO, T. G. (Org.). Geomorfologia: conceitos e tecnologias atuais. São Paulo: Oficina de Textos; 2008b. p. 74-103.

VALERIANO MM. Topodata: guia para utilização de dados geomorfológicos locais. São José dos Campos: INPE; 2008. 72p.

VALERIANO MM, ALBUQUERQUE, PCG. Topodata: processamento dos dados SRTM. São José dos Campos: INPE; 2010.

\section{CONTRIBUIÇÕES DE AUTORIA}

\section{1 - Tainara Godoy de Souza}

Centro de Engenharias, Universidade Federal de Pelotas, Bacharel em Engenharia Geológica. https://orcid.org/0000-0002-5236-9171 - tainara.engeo@hotmail.com

Contribuições: Levantamento e processamento de dados; investigação; escrita original. 


\section{2 - Áquila Ferreira Mesquita}

Departamento de Geologia e Recursos Naturais, Instituto de Geociências, Universidade Estadual de Campinas, Doutor em Ciências.

https://orcid.org/0000-0001-6159-9019 - aquila.fmesquita@gmail.com.

Contribuições: Análise de dados; escrita original; supervisão.

\section{3 - Alexandre Felipe Bruch}

Centro de Engenharias - Universidade Federal de Pelotas, Doutor em Geografia. https://orcid.org/0000-0003-1734-6799 - afbruch@gmail.com

Contribuições: Análise de dados; escrita original.

\section{COMO CITAR ESTE ARTIGO}

SOUZA, T. G.; MESQUITA, A. F.; BRUCH, A. F. Avaliação da suscetibilidade aos movimentos de massa a partir de variáveis morfométricas na interface entre 0 planalto meridional e a depressão central da região do Vale do Taquari - Rio Grande do Sul. Ciência e Natura, Santa Maria, v. 43, e44, p. 1-31, 2021. Disponível em: https://doi.org/10.5902/2179460X41243. Acesso em: dia, mês (abreviado), ano. 